\title{
Accessory navicular bone: when ankle pain does not originate from the ankle
}

\author{
Ahi Sema Issever • Kirsten Minden • Iris Eshed • \\ Kay-Geert A. Hermann
}

Published online: 28 June 2007

(C) Clinical Rheumatology 2007

The third sentence of the Discussion section should begin

"Looking at X-ray images in 1906 ...."

The online version of the original article can be found at http://dx.doi. org/10.1007/s10067-007-0624-x.

A. S. Issever · K.-G. A. Hermann $(\bowtie)$

Department of Radiology, Charité Medical School,

Charitéplatz 1,

10117 Berlin, Germany

e-mail:kgh@charite.de

K. Minden

Helios Clinics, Rheumatology Unit,

2nd Children's Hospital Berlin-Buch,

Berlin, Germany

K. Minden

German Rheumatology Research Center,

Berlin, Germany

I. Eshed

Department of Diagnostic Imaging, Sheba Medical Center,

Tel Hashomer, Israel 